Artigo / Article

\title{
Dor óssea e sua relação na apresentação inicial da leucemia linfóide aguda
}

\section{Bone pain and its relation to the initial presentation of acute lymphoblastic leukemia}

Patrícia S. Ikeuti ${ }^{1}$

Leila N. B. Borim²

Rafael L. Luporini ${ }^{3}$

\begin{abstract}
A leucemia linfóide aguda é uma neoplasia maligna do sistema hematopoiético caracterizada pela alteração do crescimento e da proliferação das células linfóides na medula óssea, com conseqüente acúmulo de células jovens indiferenciadas, denominadas blastos. É a neoplasia maligna mais freqüente (70\%) entre as crianças menores de 15 anos de idade. As manifestações clínicas mais comuns incluem febre, equimose e palidez, porém a dor óssea pode ser encontrada como sintoma inicial em $25 \%$ dos casos. Assim, com o objetivo de determinar a freqüência da dor óssea e sua relação com dados clínico-laboratoriais em crianças portadoras de leucemia linfóide aguda atendidas na unidade de Oncologia Pediátrica do Hospital de Base de São José do Rio Preto-SP, foram avaliadas cinqüenta crianças portadoras de leucemia linfóide aguda com idade até 15 anos, no período de dezembro de 1991 a dezembro de 2001. Entre as crianças estudadas, 18 apresentaram dor óssea como queixa principal e, destas, 14 apresentaram tempo de evolução (período entre primeiro sintoma e o diagnóstico) superior a 15 dias $(p=0.018)$. Além disso, 13 crianças com dor óssea e tempo de evolução superior a 15 dias apresentaram níveis de hemoglobina inferiores a 8g/dl ( $p=0,008)$. Rev. bras. hematol. hemoter. 2006;28(1):45-48.
\end{abstract}

Palavras-chave: Leucemia linfocítica aguda; osso; dor; hemoglobinometria; tempo.

\section{Introdução}

A leucemia linfóide aguda (LLA) é uma neoplasia maligna do sistema hematopoiético caracterizada pela alteração do crescimento e da proliferação das células linfóides na medula óssea, com conseqüente acúmulo de células jovens indiferenciadas, denominadas blastos. ${ }^{1}$ É a neoplasia maligna mais freqüente (70\%) entre as crianças menores de 15 anos de idade. ${ }^{2}$

Febre, palidez e equimose são as manifestações clínicas mais comuns em crianças portadoras de LLA e decorrem da falência na hematopoiese normal, devido à infiltração medular de blastos leucêmicos. ${ }^{3}$

Outras manifestações clínicas que representam infiltrações de células leucêmicas são hepatomegalia, espleno- megalia e linfadenopatia com freqüências, respectivamente, de $68 \%$, $63 \%$ e $50 \%{ }^{4}$

As dores ósseas como sintoma inicial, ocorrem em 25\% dos casos e atingem, principalmente, os ossos longos. Resultam de uma infiltração leucêmica do periósteo causando uma expansão da cavidade medular devido aos linfoblastos, ou ainda, de uma hemorragia óssea. Infiltração leucêmica da articulação também pode ocorrer causando artralgias, edemas e calor local. ${ }^{4}$

As alterações hematológicas são conseqüentes à infiltração medular. Níveis de hemoglobina $(\mathrm{Hb})$ inferiores a $10 \mathrm{~g} / \mathrm{dl}$ estão presentes em $80 \%$ dos pacientes, leucometria (Lo) superior a 10.000 células/ $\mathrm{mm}^{3}$, em aproximadamente 50\% e nível de plaquetas (Pt) inferior a 100.000 células $/ \mathrm{mm}^{3}$ em cerca de $75 \% .{ }^{4} \mathrm{O}$ diagnóstico definitivo

${ }^{1}$ Acadêmica do sexto ano de Medicina da Famerp.

${ }^{2}$ Médica responsável pela Unidade de Hematologia e Oncologia Pediátrica do Hospital de Base de São José do Rio Preto - SP.

${ }^{3}$ Acadêmico do sexto ano de Medicina da Famerp.

Famerp - Faculdade de Medicina de São José do Rio Preto

Departamento de Pediatria e Cirurgia Pediátrica do Hospital de Base - São José do Rio Preto - SP

Correspondência para: Patricia Shimoda Ikeuti

End: R. José Urias Fortes, 315 - apto 25 - Bairro São Manoel

15091-220 - São José do Rio Preto-SP

Tel.: (17) 32295220 ou (11) 82677012

E-mail: ikspaty@yahoo.com.br 
é feito através do mielograma apresentando mais de $25 \%$ de células blásticas. ${ }^{3}$ A presença de blastos leucêmicos no líquido cerebroespinal indica o comprometimento do sistema nervoso central (SNC). ${ }^{5}$

O objetivo do trabalho foi determinar a freqüência da dor óssea e sua relação com dados clínico-laboratoriais em crianças portadoras de LLA atendidas na Unidade de Oncologia Pediátrica do Hospital de Base de São José do Rio Preto-SP, usando-se para isso dados obtidos de prontuários médicos das mesmas.

\section{Casuísticas e Métodos}

Foram incluídas neste estudo cinqüenta crianças portadoras de LLA, com idade inferior a 15 anos, atendidas na Unidade de Hematologia e Oncologia Pediátrica do Hospital de Base de São José do Rio Preto, no período de dezembro de 1991 a dezembro de 2001.

As informações clínico-laboratoriais foram obtidas dos prontuários médicos. Considerou-se tempo de evolução da doença o período compreendido entre o início da queixa principal e o diagnóstico de LLA, sendo este dividido em dois grupos: precoce (tempo de evolução inferior ou igual a 15 dias) e tardio (superior a 15 dias). Os hemogramas foram obtidos na admissão, sendo que nenhum paciente recebeu transfusão sangüínea antes da sua coleta. Os mielogramas que confirmaram os diagnósticos foram colhidos em cristas ilíacas anteriores quando a idade da criança era superior a 1 ano e, em cristas ilíacas posteriores ou tíbia, quando inferior a 1 ano. Todos os exames foram realizados no Laboratório Central ou no Laboratório de Hematologia do Hospital de Base de São José do Rio Preto - SP. Na comparação dos resultados foi utilizado o teste exato de Fisher e considerado o nível de significância de 5\% $(\mathrm{p}<0,05)$.

\section{Resultados}

Foram estudadas 50 crianças portadoras de LLA, sendo 29 do sexo masculino e 21 do sexo feminino. Do total, três tinham idade inferior a 1 ano, 41 entre 1 e 10 anos e 6 tinham idade acima de 10 anos.

Entre as queixas principais, as mais freqüentes foram febre (38\%) e dor óssea (36\%). O tempo de evolução tardio foi o mais freqüente (54\%). Entre os resultados laboratoriais, alterações no hemograma como $\mathrm{Hb}<8$ g/dl, $\mathrm{Lo}<10.000$ células $/ \mathrm{mm}^{3}$ e $\mathrm{Pt}<150.000$ células $/ \mathrm{mm}^{3}$ foram encontradas em, respectivamente, 62\%, 48\% e 90\% (Tabela I).

Na avaliação da dor óssea relacionada ao tempo de evolução tardio, a freqüência de $77,8 \%$ foi estatisticamente significativa $(p=0,018)$ e não ocorreu diferença estatisticamente significativa quando a dor óssea foi relacionada com as alterações hematológicas (Tabela II).

Relacionando-se dor óssea e tempo de evolução tardio $(n=14)$ com alterações hematológicas, foi observado que o
Tabela I

Características clínicas e laboratoriais à admissão

\begin{tabular}{|c|c|c|c|}
\hline Variável & Categoria & Pacientes & $\%$ \\
\hline \multirow[t]{5}{*}{ Queixa Principal } & Febre & 19 & 38 \\
\hline & Dor óssea & 18 & 36 \\
\hline & Sangramento & 4 & 8 \\
\hline & Palidez & 3 & 6 \\
\hline & Outras & 5 & 12 \\
\hline \multirow[t]{2}{*}{$\begin{array}{c}\text { Tempo de evolução } \\
\text { (dias) }\end{array}$} & $\leq 15$ & 23 & 46 \\
\hline & $>15$ & 27 & 54 \\
\hline \multirow[t]{2}{*}{ Hemoglobina (g/dl) } & $<8$ & 31 & 62 \\
\hline & $\geq 8$ & 19 & 38 \\
\hline \multirow[t]{2}{*}{$\begin{array}{l}\text { Leucócitos } \\
\text { (células/mm³) }\end{array}$} & $<10.000$ & 24 & 48 \\
\hline & $\geq 10.000$ & 26 & 52 \\
\hline \multirow[t]{2}{*}{$\begin{array}{c}\text { Plaquetas } \\
\text { (células } / \mathrm{mm}^{3} \text { ) }\end{array}$} & $<150.000$ & 45 & 90 \\
\hline & $\geq 150.000$ & 05 & 10 \\
\hline Total & & 50 & 100 \\
\hline
\end{tabular}

Tabela II

Características da dor óssea como tempo de evolução e avaliação hematológica

\begin{tabular}{cccc}
\hline Variável & Categoria & $\%$ & $\mathrm{p}$ \\
\hline Tempo de evolução & $>15$ dias & 77,8 & 0,018 \\
& $\leq 15$ dias & 22,2 & \\
Hemoglobina $(\mathrm{g} / \mathrm{dl})$ & $<8$ & 77,8 & 0,1 \\
& $\geq 8$ & 22,2 & \\
Leucócitos & $<10.000$ & 55,6 & 0,7 \\
(céls $\left./ \mathrm{mm}^{3}\right)$ & $\geq 10.000$ & 44,4 & \\
Plaquetas & $<150.000$ & 88,9 & 1,0 \\
(céls $/ \mathrm{mm}^{3}$ ) & $\geq 150.000$ & 11,1 & \\
\hline Total & & 100 & \\
\hline
\end{tabular}

nível de hemoglobina foi estatisticamente significativo ( $\mathrm{p}=0.008$ ). Porém, ao se avaliar a relação da ausência de dor óssea e o tempo de evolução tardio com as alterações hematológicas, nenhuma variável apresentou-se estatisticamente significativa (Tabela III).

\section{Discussão}

As manifestações clínicas e a duração dos sintomas nas crianças portadoras de LLA são bastante variadas e dependem do grau de infiltração dos linfoblastos na medula óssea e da extensão do comprometimento extramedular. ${ }^{6}$ 
Tabela III

Alterações hematológicas relacionadas ao tempo de evolução $>15$ dias com dor óssea e sem dor óssea

\begin{tabular}{cccccc}
\hline \multicolumn{5}{c}{ Tempo de evolução $>15$ dias } \\
\hline Variável & Categoria & $\begin{array}{c}\text { com dor } \\
\text { óssea }\end{array}$ & $\mathrm{p}$ & $\begin{array}{c}\text { sem dor } \\
\text { óssea }\end{array}$ & $\mathrm{p}$ \\
\hline $\begin{array}{c}\text { Hemoglobina } \\
\text { (g/dl) }\end{array}$ & $<8$ & 13 & 0,008 & 6 & 0,52 \\
& $\geq 8$ & 1 & & 13 & \\
$\begin{array}{c}\text { Leucócitos } \\
\left(\text { céls } / \mathrm{mm}^{3}\right)\end{array}$ & $<10.000$ & 7 & 1,0 & 3 & 0,1 \\
& $\geq 10.000$ & 7 & & 2 & \\
$\begin{array}{c}\text { Plaquetas } \\
\left(\text { céls } / \mathrm{mm}^{3}\right)\end{array}$ & $<10.000$ & 13 & 0,33 & & \\
\hline Total & $\geq 10.000$ & 1 & & & \\
\hline
\end{tabular}

A queixa principal mais freqüentemente observada no estudo em questão foi de febre (38\%), seguida de dor óssea (36\%). Esta última é um sintoma clínico relativamente freqüente entre as crianças portadoras de $\mathrm{LLA}^{7}$ e representa 0 comprometimento leucêmico do periósteo e da cortical. ${ }^{8}$

Neste estudo, o tempo entre o início da queixa principal e o diagnóstico da LLA foi denominado tempo de evolução precoce (quando inferior ou igual a 15 dias) ou tardio (quando superior a 15 dias). Entre as crianças estudadas, 54\% (27) apresentaram um tempo de evolução denominado tardio. Na relação entre o tempo de evolução tardio e as principais queixas clínicas avaliadas, a única queixa estatisticamente significativa foi a dor óssea $(\mathrm{p}=0,018)$.

A dor óssea e a dor articular são sintomas clínicos relativamente freqüentes entre as crianças portadoras de $\mathrm{LLA}^{7}$ e refletem um envolvimento leucêmico do periósteo, ou de todo o osso, e/ou uma infiltração leucêmica na articulação. ${ }^{4}$ Por outro lado, estas manifestações clínicas podem ser erroneamente interpretadas como a manifestação de uma doença não neoplásica, como a artrite reumatóide juvenil ou a osteomielite, e causarem um atraso no diagnóstico da LLA. ${ }^{9,10,11}$

Cabral \& Tucker estudaram retrospectivamente 29 crianças menores de 15 anos de idade, portadoras de diversas neoplasias e com o diagnóstico clínico de uma doença reumática, entre as quais a queixa clínica de dores músculo-esqueléticas foi a mais referida. A artrite reumatóide juvenil foi a suspeita diagnóstica mais freqüente entre tais pacientes.

O tempo entre avaliação de um médico reumatologista e o diagnóstico de uma neoplasia variou de zero a 172 dias e a neoplasia mais freqüentemente diagnosticada entre essas crianças foi a LLA. Foi concluído que em crianças com queixas sugestivas de uma doença reumática é importante avaliar como diagnóstico diferencial neoplasias (entre elas LLA). ${ }^{12}$
Matysiak et al, em um estudo referente ao quadro clínico de dor articular e/ou dor em membros inferiores entre crianças portadoras de LLA, demonstraram um tempo de evolução prolongado, dificuldade diagnóstica e alterações hematológicas discretas ou ausentes nesses casos. ${ }^{11}$

No estudo em questão não ocorreram diferenças estatisticamente significativas entre dor óssea e alterações hematológicas, embora tenham ocorrido maiores freqüências de $\mathrm{Hb}>8 \mathrm{~g} / \mathrm{dl}$ e $\mathrm{Pt}<150.000$ células $/ \mathrm{mm}^{3}$ neste grupo. Esta maior freqüência também foi descrita na literatura em um estudo retrospectivo de todos os pacientes com diagnóstico de LLA que receberam tratamento no Childrens Medical Center of Dallas - USA durante um período de 13 anos para determinar a relação entre a presença de dor óssea ao diagnóstico e as alterações hematológicas no sangue periférico. Os autores observaram que as crianças portadoras de LLA com dor óssea proeminente e precedendo o diagnóstico têm, freqüentemente, valores hematológicos normais ou pouco alterados e um tempo de evolução prolongado da queixa clínica. Além disso, os pacientes também apresentaram leucometria, níveis de hemoglobina e contagem de plaquetas tendendo à normalidade, com os blastos em sangue periférico ausentes ou raros. Os referidos autores concluíram, então, que estes resultados podem ter contribuído para um atraso no diagnóstico da LLA. ${ }^{13}$ Porém, no estudo relatado houve diferença estatisticamente significativa $(\mathrm{p}=0.08)$ quando se comparou dor óssea e tempo de evolução tardio com níveis de hemoglobina menores que $8 \mathrm{~g} / \mathrm{dl}$.

\section{Conclusão}

A leucemia linfóide aguda é a neoplasia maligna mais freqüente em crianças menores de 15 anos e pode apresentar-se com febre, palidez e equimose. Entretanto, a dor óssea pode ser o primeiro sintoma em cerca de $25 \%$ dos casos. ${ }^{4}$ Por isso, a LLA deve-se ser investigada em crianças que se apresentem com dor óssea.

Conclui-se, através dos resultados obtidos neste estudo, que a dor óssea contribui para o atraso no diagnóstico de LLA, estando ambos (dor óssea e atraso diagnóstico) conjuntamente, associados à diminuição acentuada dos níveis de hemoglobina em crianças portadoras de LLA.

\section{Abstract}

Acute lymphoblastic leukemia is a hematopoietic malignancy characterized by alterations in the growth and proliferation of lymphoblastic cells in bone marrow, with consequent accumulation of immature white blood cells called blasts. It is the most common malignant neoplasm seen in under fifteen-year-olds. Acute lymphoblastic leukemia frequently presents with fever, ecchymosis and paleness, however bone pain is the initial symptom found in $25 \%$ of the cases. The objective of this work is to determine the frequency of bone pain and its relation with clinical and laboratory data in children with acute lymphoblastic leukemia admitted in 
the Pediatric Oncology Unit of Hospital de Base de São José do Rio Preto, São Paulo, Brazil. Fifty children with acute lymphoblastic leukemia, aged under fifteen years old, in the period from December 1991 to December 2001 were assessed. Among the children studied, 18 presented bone pain as the main complain and of these, 14 presented a time of evolution (period between first symptom and diagnosis) of over 15 days $(p=0.01)$. Moreover, 13 children with bone pain and time of evolution greater than 15 days had hemoglobinometry below $8 \mathrm{~g} / \mathrm{dL}(p=0.008)$. Rev. bras. hematol. hemoter. 2006;28(1):45-48.

Key words: Acute lymphocytic leukemia; bone pain; hemoglobinometry; time.

\section{Referências Bibliográficas}

1. Lanzkowsky P. Leukemias. In: Lanzkosky P, editor. Manual of Pediatric Hematology and Oncology. 2a ed. New York: Churchill Livingstone; 1995. p.293-345.

2. Parkin DM, Stiller CA, Draper GJ et al. The international incidence of childhood cancer. Lyon: Word Health Organization, IARC Scientific Publication; 1988b. n. 87.

3. Van Der Does-Van Den Berg A, Bartram CR et al. Minimal requirements for the diagnosis, classification, and evaluation of the treatment of childhood acute lymphoblastic leukemia ( ALL ) in the 'BFM Family' Cooperative Group. Med Pediatr Oncol 1992;20:497-505.

4. Margolin JF, Poplack DG. Acute Lymphoblastic Leukemia. In: Pizzo PA, Poplack DG, editores. Principles and Practice of Pediatric Oncology. $3^{\mathrm{a}}$ ed. Philadelphia: JB Lippincontt Company; 1997. p.409-462.

5. Mastrangelo R, Poplack D, Bleyer A et al. Report and Recommendations of the Rome Workshop concerning poor-prognosis acute lymphoblastic leukemia in children: biologic bases for staging, stratification, and treatment. Med Pediatr Oncol 1986;14:191-194.

6. Lopes LF. Estudos pré-leucêmicos na infância: estudo clínico e hematológico [dissertação]. Campinas (SP): Faculdade de Ciências Médicas da Universidade Estadual Campinas; 1994.

7. Ma SK, Chang GC, Chiu DC et al. Clinical presentation, hematologic features and treatment outcome of childhood acute lymphoblastic leukemia: a review of 73 cases in Hong Kong. Hematol Oncol 1997;15: 141-149.

8. De Camargo B, Lopes LF. Leucemias na Infância. In: Pediatria Oncológica. Noções Fundamentais para o Pediatra. 1a ed. São Paulo. Lemar; 2000: p.109-118.

9. Costelo PB, Brecher ML, Starr JI et al. A prospective analysis of the frequency, course and prognostic significance of the joint manifestations of childhood leukemia. J Rheumatol 1983;10:753-757.

10. Tsai MJ, Yan DC, Chiang BL et al. Childhood leukemia mimicking juvenile rheumatoid arthritis. Act Paediatr Sinica 1995;36:274-278.

11. Matysiak M, Ochocka M, Armata J et al. Vertebral column involvement as a first manifestation of childhood leukemia [abstract]. Med Pediatr Oncol 1996;27:291.

12. Cabral DA, Tucker LB. Malignancies in children who initially present with rheumatic complaints. J Pediatr 1999;34:53-57.

13. Jonsson OG, Sartain P, Ducore JM et al. Bone pain as an initial symptom of childhood acute lymphoblastic leukemia: association with nearly normal hematologic indexes. J Pediatr 1990;117:233-37.

Avaliação: Editor e dois revisores externos.

Conflito de interesse: não declarado

Recebido: 15/10/2005

Aceito após modificações: 17/12/2005 